\title{
Reconstruyendo la antropología filosófica: entre naturaleza y cultura
}

\author{
RAFAEL ALVEAR* \\ Universidad Adolfo Ibáñez (Chile) \\ rafael.alvear@edu.uai.cl
}

\begin{abstract}
Resumen
La antropología filosófica emerge como una subdisciplina interna a la filosofía que procura sistematizar los esfuerzos por responder la pregunta acerca de qué es el ser humano. En ella, el nivel de autoconsciencia que alcanza dicha interrogante es inobjetable. La antropología filosófica no es una mera forma intelectual de acercamiento al ser humano, sino que es pensamiento sobre el ser humano par excellence. Sin embargo, cabe preguntarse: ¿cuál es la especificidad estructural que ofrece la misma? A continuación, se persigue reconstruir el núcleo conceptual que desarrolla la antropología filosófica desde sus primeros bosquejos en Kant hasta su realización sistemática en Scheler, Plessner y Gehlen. $\mathrm{Al}$ respecto, será posible constatar una estructura teórica bidimensional enraizada en dos polos distantes, pero íntimamente entrelazados, a saber: naturaleza y cultura.
\end{abstract}

Palabras clave: Antropología filosófica, naturaleza, cultura, ser humano en bruto, sujeto.

\section{Reconstructing philosophical anthropology: between nature and culture}

\begin{abstract}
Philosophical anthropology emerged as an internal subdiscipline of philosophy that aimed to systematize the efforts for answering the question about what the human being is. Within it, the level of self-consciousness that this question evokes is beyond doubt. Philosophical anthropology is not merely an intellectual way of grasping the human being, but thinking about the human being par excellence. Nonetheless, what is the structural specificity that this philosophical orbit offers? This article intends to reconstruct the conceptual core that philosophical anthropology developed, from its first outlines in Kant until its systematic realization in Scheler, Plessner and Geblen. In that regard, it will be possible to verify a two-dimensional structure which is rooted in two distant but deeply-linked poles: nature and culture.
\end{abstract}

Key words: Philosophical anthropology, nature, culture, raw buman being, subject.

* $\quad$ Doctor en Sociología por la Universidad de Flensburg (Alemania). Entre sus publicaciones destaca el libro Soziologie obne Mensch? Umrisse einer soziologischen Anthropologie (2020).

Este artículo es una versión reelaborada de una ponencia presentada en el Coloquio "Probleme der Gesellschaftstheorie" de la Universidad de Flensburg (Alemania) en Julio de 2015, el cual fue parte además de mi tesis de doctorado Die Stellung des Menschen in der zeitgenössischen Soziologie. Umrisse zu einer soziologischen Anthropologie (2018). Agradezco a Hauke Brunkhorst por sus observaciones al texto en alemán, así como a Pablo Beytía por sus comentarios a esta versión en español. La preparación de este escrito cuenta con el apoyo de CONICYT, en particular del Programa Fondecyt de Postdoctorado 2019, Proyecto $\mathrm{N}^{\circ}$ 3190389. La traducción de las citas en alemán es de mi autoría. 
INTRODUCCIÓN

$\mathrm{Al}$ observar la reflexión filosófica respecto al ser humano no resulta difícil advertir el carácter inmanente que ostenta dicha relación. Desde que existe pensamiento crítico, el ser humano ha sido objeto de especulación sin restricción alguna: ¿De dónde viene?, ¿hacia dónde va? y ¿qué o quién es finalmente el ser humano?, son interrogantes que han tenido lugar en la filosofía desde tiempos inmemoriales y que, no obstante aquello, alcanzan su momento cumbre con el surgimiento de una dirección de pensamiento en particular. Aun cuando el quehacer filosófico -al menos desde los griegos en adelante- ya se preguntaba desde diferentes ópticas por el ser humano (Landmann, 1962), no es sino con la antropología filosófica que aquel tipo de reflexión adquiere una figura uniforme y autoconsciente. La antropología filosófica es una subdisciplina de la filosofía que encuentra sus primeros contornos explícitos en Kant (Schnädelbach, 1983: 272; Sobrevilla, 2006), pero que adopta una imagen clara en la obra de Max Scheler, Helmuth Plessner y Arnold Gehlen, entre otros. Más allá de la trascendencia y la inabarcabilidad del pensar filosófico acerca del ser humano, resulta evidente que dicha empresa teórica expresa un momento cúlmine. La antropología filosófica no es una mera forma intelectual de acercamiento al ser humano, sino que es pensamiento sobre el ser humano par excellence.

La centralidad que ostenta aquel marco de pensamiento no lo ha eximido en todo caso de críticas. Estas últimas han contribuido incluso a su masividad contextual. Ya desde su expansión a inicios del siglo XX son diversas las voces que aparecen para ponerla en tela de juicio. El autor de la obra que por esos años generará un quiebre en la filosofía alemana, me refiero a Sein und Zeit de Martin Heidegger, sostuvo que la antropología filosófica, al concentrarse en el ser humano, sólo pondría la atención en un campo específico del ser-ahí [Dasein], sin comprender que la interrogante fundamental tendría que ver más bien con aquella dimensión ontológica supra-humana en cuanto tal (Heidegger, 1997; Landmann, 1969: 4748). Asimismo, la teoría crítica observó con permanente escepticismo, a partir de la denominada sospecha antropológica [Anthropologieverdacht] (Raulet, 2013: 33), cada uno de los intentos por dar cuenta del ser humano en términos intrínsecos (véase en particular la crítica acerca de su ahistoricismo, en Horkheimer, 1935; también por parte de Lukács (1923: 174ss.); o incluso después Habermas (1962)). Ambas ópticas, tal como lo ha afirmado Herbert Schnädelbach (1983: 280-281), darían cuenta del movimiento filosófico de desmarque o despedida frente al antropocentrismo moderno [Abschied vom neuzeitlichen Anthropozentrismus], cuyo proceso la antropología filosófica, paradójicamente, habría acelerado. 
Sin embargo, antes de cualquier movimiento de distancia, tiene que haberse formado aquel marco filosófico implicado en éste. De tal forma, cabe preguntarse en lo que sigue: ¿Cuál es la especificidad estructural que ofrece la antropología filosófica? ¿Qué imagen de ser humano comporta dicha tradición? ¿Cuál es el núcleo constitutivo de su forma de observar al ser humano? El objetivo de este artículo es reconstruir la estructura central de la comprensión que desarrolla la antropología filosófica acerca del ser humano. Con tal propósito en mente, se organiza el texto de la siguiente manera: en una primera sección se persigue exponer sucintamente el núcleo general que ostenta la antropología filosófica. Aquí intentaré dar cuenta de la posición de privilegio en que se encuentra la distinción que hace Kant entre antropología fisiológica y antropología pragmática. Esta distinción, adoptada luego por Scheler, Plessner y Gehlen, se basa en una previa diferenciación entre competencias antropológicas de carácter fisiológicas y culturales [1]. En una segunda y tercera sección, me hago cargo de ambas dimensiones de manera más sistemática. Mientras que la dimensión fisiológica [2] presume la existencia de una suerte de condición natural del ser humano -en tanto Rohmensch o ser bumano en bruto- que pone el acento en su raigambre corporal, la dimensión cultural [3] permite reparar en el desarrollo posterior del mismo -en tanto que sujeto-, como ser capaz de reflexión, distancia cognitiva y acción. Hacia el final se persigue exponer el carácter indisociable que muestran ambas dimensiones desde la perspectiva de la antropología filosófica. Mientras que la primera da cuenta del sustrato natural-basal de los seres humanos, la segunda remite a la vía cultural que han tomado estos últimos en la búsqueda de su autorrealización [4].

\section{ANTROPOLOGÍA FISIOLÓGICA Y PRAGMÁTICA}

La búsqueda por dar cuenta del núcleo estructural que define a la antropología filosófica obliga a retornar a su primera demostración explícita en Kant. Luego del apogeo filosófico de Pascal y Herder, Kant ingresa al debate sobre la antropología en 1798 con su lección pre-crítica Anthropologie in pragmatischer Hinsicht, a partir de la cual el ser humano alcanza una posición dominante al interior del pensamiento filosófico. Sustentada en su variante antropológica, la filosofía podría estar en condiciones de determinar "los aspectos esenciales de la naturaleza humana" y, asimismo, establecer "los principios de un sistema de conocimiento filosófico" (Becker, 1983: 12). La posición concéntrica que Kant le atribuye a la antropología está además en consonancia con la famosa división de campos que se observa en sus lecciones sobre lógica, llevadas a cabo desde la mitad del siglo XVIII y publicadas en 1800. En ellas queda claro que la filosofía ha 
de poner el foco en las siguientes preguntas: “1) ¿Qué puedo saber? 2) ¿Qué debo hacer? 3) ¿Qué puedo esperar? 4) ¿Qué es el ser humano? La primera la responde la metafísica, la segunda la moral, la tercera la religión y la cuarta la antropología. En el fondo, podría, sin embargo, considerarse todo ello como parte de la antropología, dado que las tres primeras preguntas se refieren a la última" (Kant, 1978: 448).

Uno de los elementos más importantes desarrollados por Kant en su Anthropologie in pragmatischer Hinsicht reside en la introducción de una particular distinción, a saber: de la distinción entre la antropología fisiológica y la antropología pragmática. Aquella diferenciación, que contribuirá al ordenamiento teórico de la mencionada antropología filosófica -al menos como programa teórico o investigativo (Fischer, 2006: 64)- exhibe una estructura clara. Por una parte, la antropología fisiológica -también entendida recurrentemente como antropología biológica- se ocupa de investigar lo que "la naturaleza hace del ser humano" (Kant, 1983: 29). En ello se destaca, como veremos, la dimensión fisiológica o genérica del ser humano, según la cual el mismo aparece como mero espectador, dejando a la naturaleza hacer a su voluntad (Kant, 1983: 29). "Con respecto a su relación con el mundo el ser humano se experimenta (...) como un ser" determinado por aquello que la naturaleza dispone (Becker, 1983: 18). Y de ahí que el ser humano deba ser comprendido primeramente como ser vivo (Landmann, 1969: 123).

Por otra parte, la antropología pragmática se aboca al estudio de aquello que el ser humano "en tanto que agente libre hace, o puede y debe hacer, de sí mismo” (Kant, 1983: 29), con lo cual se acentúa su dimensión cultural. Por cierto que dicha dimensión está en sintonía con una suerte de esfera accionalista, en la medida en que el ser humano en definitiva hace algo de sí mismo. Sin embargo, dicha esfera de acción aún no es comprendida en términos propiamente sociológicos -como lo será después, por ejemplo, en el caso de Max Weber-, sino que sobre la base de un ser humano prácticamente aislado, que se fija propósitos o metas en pos de desplegarse a sí mismo. En contraposición a los (otros) animales, el ser humano detentaría una relación abierta con respecto al mundo, que le permite incidir en su entorno o en sí mismo, así como perseguir fines que "no le son dados por la naturaleza, sino que ideados y definidos por él" (Becker, 1983: 18). La antropología pragmática aspira, por tanto, a observar y analizar al ser humano y su comportamiento cultural (Becker, 1983: 24).

A partir de lo anterior puede reconocerse más sencillamente el complemento recíproco de ambos polos. Ambos están "conformados con relación al otro. La antropología biológica y la filosófica-cultural están entrelazadas" (Landmann, 1969: 160), éstas se presuponen mutuamente y formarían una unidad que, no obstante lo precedente, no resulta ajena a 
dificultades. Detrás de la unidad sostenida por ellas no se hallaría otra cosa que una suerte de rivalidad conceptual; una lucha, como ha señalado Schnädelbach (1983: 274ss.), entre las imágenes naturalistas y culturalistas -o bistórico-culturales- del ser humano por el monopolio de las formas interpretativas. Mientras que el primer tipo de imagen permanece ligado al enfoque biológico -así como abstraído hasta cierto punto del segundo-, este último está conectado con una perspectiva histórica-cultural -igualmente abstraída del primero-, según la cual la historia es comprendida incluso parafraseando el entender kantiano- como aquel ámbito cultural que emerge como resultado de lo que "el ser humano hace en libertad de sí mismo" (Schnädelbach, 1983: 276). Si, por una parte, la perspectiva biológica o fisiológica apunta a captar la constitución innata del ser humano, el prisma pragmático persigue, por otra parte, dar cuenta del desarrollo cultural de tales características humanas. Es este último el que permite además comprender el carácter no-predeterminado, sino que histórico de la cultura humana en general (Agard, 2013: 177).

Al observar el devenir filosófico posterior a Kant, no resulta difícil constatar cómo es que aquella unidad formada por la antropología fisiológica y pragmática preconfigura el núcleo teórico de la que será luego conocida en sentido estricto -junto a nombres como Max Scheler, Helmuth Plessner y Arnold Gehlen- como antropología filosófica. Si bien con diferentes matices, los tres mencionados representantes de la antropología filosófica de inicios del siglo XX asientan sus teorizaciones en aquella distinción -baste aquí, sin embargo, con enunciar esto último brevemente. La antropología filosófica de Scheler, quien es considerado como el fundador fáctico de dicha dirección de pensamiento, se basa en una dualidad que recrea la distinción entre antropología fisiológica y pragmática, y toma la forma de un equilibrio mutuamente penetrante [gegenseitig durchdringenden Ausgleichs] (Scheler, 2010: 51). Esta suerte de balance, que encuentra manifestación en realidades de diversa naturaleza (Scheler, 1929: 47-83), se cristaliza de manera antropológica en una "doble-participación del ser humano en el fundamento del mundo" (Henckmann, 1998: 223). Y es esto mismo lo que queda expuesto en su obra maestra. Al comienzo de Die Stellung des Menschen im Kosmos de 1928, Scheler asume que el concepto de ser bumano contiene una ambigüedad que termina por precisar el leitmotiv de su exploración antropológico-filosófica. Mientras que la palabra ser humano

indica primero las características que el ser humano posee como subgrupo de las especies de vertebrados y mamíferos [de manera que se supedita al concepto de animal; M.S.] (...) la misma palabra 'ser humano' señala, sin embargo, en el lenguaje de la vida cotidiana, en todos los pueblos civilizados, algo absolutamente diferente (...) Quiero llamar a este segundo concepto el 
concepto esencial de ser humano, en contraposición al primer concepto sistemático-natural. Nuestro tema al respecto es si es que este segundo concepto, que le otorga al ser humano como tal una posición especial, que la hace incomparable con el resto de las posiciones que ostentan las especies vivas, está en lo cierto o no. (Scheler, 2010: 7-8)

Si la unidad de la antropología fisiológica y pragmática encuentra expresión visible en Scheler a través de la idea del equilibrio o balance, ésta adquiere en Plessner la forma de una equivalente mediación, de un permanente ir y venir de la mediación [leeren Hindurch der Vermittlung]. Aquella conciliación de ambas dimensiones se manifiesta antropológicamente en un carácter o aspecto-doble del ser humano que acaba por coronar el elemento central de su antropología filosófica. También al inicio de su obra fundamental Die Stufen des Organischen und der Mensch de 1928, Plessner justifica en general el rol de la antropología filosófica en virtud de dicha bidimensionalidad:

Si a partir de lo anterior debe haber una ciencia [como la antropología filosófica; R.A.] que comprenda la experiencia que el ser humano tiene de sí, de cómo él vive y registra su vida históricamente (...) entonces no puede ni le está permitido a dicha ciencia limitarse al ser humano en tanto que persona, en tanto que sujeto de creación intelectual, de responsabilidad moral, de obediencia religiosa, sino que debe intentar comprender el círculo completo de la existencia y de la naturaleza que está al mismo nivel esencial que la vida personal (...) En estas dos direcciones se puede tener esperanza de asir realmente al ser humano como sujeto-objeto de la cultura y como sujeto-objeto de la naturaleza. (Plessner, 1975: 27, 32)

Algo similar puede desde luego observarse en Gehlen, quien postuló a la antropología filosófica como un tipo de ciencia integrativa (Gehlen, 1983: 405). A pesar de que esta última es asociada con frecuencia a la vieja separación cuerpo-alma, lo que se revelaría como un mero prejuicio teórico (Gehlen, 1983: 51; 1966: 12), aquella también denominada ciencia total del ser bumano procura registrar ambas dimensiones del ser humano al mismo tiempo, a saber: la fisiológica y la cultural. Esta unidad es la que permitiría formar un sistema "de relaciones lógicas y recíprocas de todas las características esenciales del ser humano, desde el caminar erguido hasta la moral" (Gehlen, 1966: 17). La obra principal de este representante de la famosa e igualmente criticada Escuela de Leipzig Der Mensch. Seine Natur und seine Stellung in der Welt de 1940 se erige justamente como un intento por corresponder aquella totalidad del ser bumano de manera sistemática.

Así las cosas, queda claro grosso modo que la antropología filosófica se levanta a partir de un primer acercamiento a los "resultados investigativos 
de la antropología” biológica y cultural (Lepenies, 1977: 9-10; Habermas, 1962: 18) para así incluso aspirar a dar cuenta del "fundamento de las ciencias naturales y culturales del ser humano" (Eßbach, 2007: 3). Si bien la relación con la biología o fisiología ha sido destacada como un factor clave para todos los representantes de la antropología filosófica del siglo XX (Fischer, 2006: 68), la dimensión pragmática o cultural no carece de importancia. Más allá de las diferentes perspectivas y baterías conceptuales que son desplegadas por los mismos, resulta evidente que la antropología filosófica persigue ocuparse de ambas dimensiones antropológicas en pos de captar la complejidad del ser humano en su totalidad. Siguiendo aquella distinción, trazada inicialmente por Kant, la antropología filosófica debe entonces, como lo resume Jürgen Habermas (1962: 19), recopilar aquello que las ciencias individuales saben objetivamente sobre el ser humano sobre lo que la naturaleza hace del ser humano- para interpretar el sentido de lo que ocurre posteriormente con él -de lo que el ser humano hace consigo mismo. A partir de dicho fundamento sería luego posible entregar una respuesta a la pregunta por la particularidad del ser humano como un todo.

\section{Hacia una perspectiva de competencias antropológicas}

Visto desde una perspectiva más abstracta, no resulta difícil reconocer una singular estructura detrás de ambas dimensiones, la que puede categorizarse junto al antropólogo Dieter Claessens mediante el concepto de competencia. Aun cuando la noción de competencia de Claessens (1973) es utilizada sobre todo para acentuar la importancia de facultades como la lingüística, la sexual y la social, esta misma, como lo sostiene Wolf Lepenies (1977), no se limita a lo anterior. La diversidad de temas y espacios en los que aquel concepto ha sido empleado -desde Chomsky a Habermas- da cuenta de la plasticidad de su condición; la que no por nada ha terminado por abrir el camino para el desarrollo de una sociología de la competencia de talante propiamente antropológico (Kurtz \& Pfadenhauer, 2010; Kurtz, 2010: 17-19). Al margen de sus diferentes formas de uso, su significado nuclear se observa claro: la idea de competencia descansa en la potencialidad general de "disposiciones, menesteres, facultades para la satisfacción de necesidades, así como en las habilidades desarrolladas a propósito de lo anterior" (Claessens, 1973: 151). Desde el prisma de una antropología filosófica, la idea de competencia es entendida entonces como una especificación antropológica de naturaleza evolutiva que depende de su realización a través de ofertas de aprendizaje (Claessens, 1973: 151; también Griese, 1976: 106) y se cristaliza en las dos mencionadas dimensiones del ser humano. 
Ya sea de carácter fisiológico o pragmático, lo que se esconde detrás de dicha distinción no es otra cosa que una comprensión acerca de las competencias que el ser humano ostentaría desde su nacimiento y su posterior inclusión en el mundo cultural. Partiendo de esa base se torna más sencillo observar por qué el ser humano es concebido como una consecuencia de la evolución natural y cultural, entre otras (Claessens, 1973: 147). Si éste dispone de una serie de competencias fisiológicas y culturales, es porque la evolución -en un sentido amplio- lo ha hecho posible. Sin embargo, más allá de la forma en que el ser humano ha adquirido tales competencias en dicho proceso evolutivo, ambas dimensiones aluden en definitiva a aquello que la perspectiva antropológico-filosófica identifica como la base fisiológica y el desarrollo o la culminación cultural del ser humano (Landmann, 1969: 186, 188). De este modo, se manifiesta una forma dual de comprender a la naturaleza humana sobre la base de propiedades "que engloban el nexo de la 'naturaleza' 'natural' (fisiológica y biológico-evolutiva, etc.) con la 'naturaleza' 'cultural' (personal, social, etc.) del ser humano" (Müller y Heilinger, 2008: 190). Más allá de dicha mencionada conexión, cabe detenerse en cada una de manera separada, para así obtener una imagen completa de aquel horizonte antropológico-filosófico.

\section{LA DIMENSIÓN FISIOLÓGICA DEL SER HUMANO}

El entrelazado del ser humano con la naturaleza asoma evidente, como se observa, en la primera dimensión. El objeto de dicha perspectiva antropológica es el "ser humano como género", el "que se compara con otras especies animales en términos morfológicos y fisiológicos" (Habermas, 1962: 18). Este punto de vista alude por lo mismo a aquellas competencias o capacidades de las cuales el ser humano dispone desde su nacimiento y que luego pueden ser "puestas en movimiento a través del entorno cultural", en la vida cotidiana (Griese, 1976: 106). Si, sin embargo, aquella potencialidad del ser humano puede ser ampliada o ejercida en el contexto cultural, esto se debe a la posibilidad que tiene él mismo de hacer uso de aquellas competencias que posee desde un inicio por el hecho de haber nacido bumano. Por esta razón, el ser humano ha de ser entendido según esta óptica - primero que todo- como un "ser vivo" que, en cuanto tal, está supeditado a la ley de la herencia natural (Landmann, 1969: 123: 199). 
A pesar de estar desprovista de una consideración acabada al respecto, es posible ya rastrear un tipo de definición fisiológica en Kant ${ }^{1}$. Al observar sus escritos antropológicos se puede captar la base material (fisiológica) de lo que será luego la comprensión pragmática de la razón. Kant mismo terminó por asumir que la "sistematicidad de su antropología se funda en una estructura basal de la capacidad del espíritu (conocimiento, sensación y deseo)" (Sturm, 2010: 94). A partir de aquello no resulta difícil "afirmar: el primer carácter de la especie humana" reside en "la capacidad" técnico-material para "ser racional" (Kant, 1983: 287). Esta suerte de disposición o equipamiento técnico natural [technische Naturanlage], como lo define el filósofo de la ilustración (Kant, 1983: 279 ss.), que deja ver al ser humano fisiológicamente como un animal disponible para el ejercicio de la razón, ya resultaría observable -como se repetirá luego en Gehlen- en la "forma y organización de su mano, de sus dedos y yemas del dedo, cuya conformación y sentido de la delicadeza" permiten comprender que la "naturaleza no lo ha hecho inteligente para un tipo de manejo de las cosas, sino que indeterminadamente para todas $y$, por consiguiente, para el uso de la razón” (Kant, 1983: 280). Es esto último, prosigue Kant, lo que justamente permite "valorar la disposición hábil o técnica de su especie como la de un animal racional" (Kant, 1983: 281).

En el caso de los representantes más importantes de la antropología filosófica del siglo XX, este ámbito fisiológico descansa en una concepción filosófica de la corporalidad [Leiblichkeit], desarrollada a partir del acercamiento a material empírico proporcionado por científicos como Gustav Fechner, Charles Darwin, Karl Bühler, Konrad Lorenz e Iwan Pawlow, entre otros. El primer polo interno de la figura del equilibrio, que apunta a dicha dimensión corporal, se corresponde en Scheler con categorías o competencias como el impulso afectivo extático, el instinto, la memoria asociativa y la inteligencia práctica, todos los cuales conforman tal etapa fisiológica general. Mientras que el impulso afectivo extático es compartido por plantas, animales y seres humanos, el instinto, la memoria asociativa e incluso -

1 Como Thomas Sturm (2010) lo ha señalado, tal esfera fisiológica carece en la obra de Kant de un correlato sistemático (ver también Kant, 1983: 279). Un vistazo rápido a la antropología kantiana da cuenta de su irrelevancia (Kant, 1983: 99). Preocupado por el desarrollo de una antropología de carácter pragmático, Kant rechazó explícitamente las explicaciones fisiológicas -identificadas en su tiempo junto a Ernst Platner, entre otrosen la medida en que éstas son parte de disciplinas empíricas que contemplan al ser humano como producto de la naturaleza y no ofrecen material importante para la comprensión de su vida cultural -en tanto que co-diseñador de su destino. De tal manera, aquellas explicaciones fisiológicas sólo pueden ser entendidas como vanas (Kant, 1983: 99), secundarias para el desarrollo de su investigación histórica de orientación pragmática (Sturm, 2010: 95). 
hasta cierto punto- la inteligencia práctica, son compartidas por animales y seres humanos (Scheler, 2010: 9-26). Con estas competencias quedan expuestas las funciones y facultades que distinguen el carácter basal de la esfera vital. Para Scheler, "[l] corriente de fuerzas y causas que de manera única puede definir la existencia y la forma accidental del ser, no corre en este mundo que habitamos de arriba hacia abajo, sino que ¡de abajo hacia arriba! (...) Cada forma de existencia superior es, con respecto a la inferior, relativamente endeble - y ésta no se realiza a través de sus propias fuerzas, sino que a través de las fuerzas de las inferiores" (Scheler, 2010: 47-48). El ser humano es por tanto dependiente de un impulso vital [Lebensdrang], cuyo poder y fuerza termina por fungir, como se verá más adelante, como motor corporal de su vida cultural.

Aquel esquema progresivo puede también encontrar expresión espacial. En Plessner, las plantas, los animales y los seres humanos son examinados en su relación respectiva con el "ambiente, entorno y mundo; su 'forma posicional', la relación en que están cuerpo y entorno" se convierte así en punto clave para la determinación fisiológica del ser humano (Habermas, 1962: 24). Aquella raigambre material queda marcada a través de una posición céntrica que se ofrece como el lado basal del carácter doble del ser humano y es vivenciado -también por los animales- como cuerpo [Leib]. En tanto que cuerpo el ser humano está posicionado, como el animal, de manera céntrica y está integrado a su vez en entornos diferenciados, "perceptibles a través de procesos de acoplamiento neuronal" (Fischer, 2006: 73). El ser humano permanece en su centro posicional, dependiente del aqui-ahora, en la medida en que él es su cuerpo [er ist sein Leib] y no puede desprenderse del mismo. Como parte del reino animal, el ser humano experimenta impulsos en el ambiente, lo ajeno y lo propio, sin poder tomar distancia respecto de ellos, respecto de su propio cuerpo. Visto fisiológicamente, éste sería capaz de dominar su cuerpo, pero no de "vivenciarse a sí mismo" (Plessner, 1975: 288).

Como se deja ver en lo anterior, la antropología filosófica no sólo gira en torno a las capacidades del ser humano, sino que también a sus incapacidades -lo que por cierto se manifiesta igualmente en términos fisiológicos. A pesar de que el diagnóstico sobre las debilidades del instinto humano en comparación con las del animal, así como sobre la falta de especialidad de su dotación orgánica son elementos fundamentales de la antropología filosófica en general (Habermas, 1962: 22), es primeramente Gehlen quien afina dicho enfoque y lo radicaliza. En correspondencia con la categorización que Nietzsche realiza del ser humano como de aquel animal indeterminado, Gehlen comprende al ser humano como inacabado [unfertig] y al mismo tiempo condicionado por sus carencias. Aquellas carencias son denomina- 
das en un sentido biológico como "inadecuaciones, falta de especializaciones, primitivismo, esto es: como falta de desarrollo" (Gehlen, 1966: 33). Para Gehlen, falta

pelaje y con ello la protección natural contra la intemperie; faltan los órganos de ataque natural, pero también una formación corporal adecuada para huir; el ser humano es sobrepasado en agudeza de sentidos por la mayor parte de los animales, él tiene incluso una carencia peligrosa de instintos originales y está sujeto durante todo el período de lactancia y de niñez a una necesidad de protección completa e incomparablemente larga. En otras palabras: sometido a condiciones naturales, él habría sido erradicado hace tiempo entre los animales de presa más diestros y los animales depredadores más peligrosos. (Gehlen, 1966: 33)

Sin perjuicio de los conceptos, perspectivas o metáforas que son utilizados por los distintos representantes de la antropología filosófica, el ser humano es definido al interior de esta dimensión de manera genérica, según lo cual el acento se sitúa en su distinción y/o sobre todo en su identidad respecto de lo animal. Aquella paradójica comparación ser humano/animal, que ya es observable en los griegos, es constitutiva, como lo ha sostenido Joachim Fischer (2006: 70), para la formación conceptual de la antropología filosófica en general y permite abrir las puertas para una comprensión más sistemática de la imagen de ser humano proyectada a este nivel. Sin importar la diversidad de formas que alcanza esta variante antropológica, se vuelve en cualquier caso evidente que dicha dimensión fisiológica o genérica da cuenta de una batería de competencias que conforman aquella disposición técnica natural que marca al ser humano como especie animal y se erige luego como base indispensable para su realización cultural.

\section{El ser bumano en bruto}

A partir de lo expuesto anteriormente se puede advertir más sencillamente por qué el ser humano es comprendido en términos fisiológicos "como una pura posibilidad" (König, 1965: 40); una pura posibilidad que puede ser resumida en el concepto de ser bumano en bruto [Rohmensch]. Una consideración del ser humano en una suerte de estado primario natural [im Rohzustand] parece ganar en importancia, toda vez que alude a las competencias o propiedades de la especie bumana en cuanto tal. Kant mismo se refirió en diferentes momentos a dicha condición brutal o cruda [Robigkeit], a aquel ser bumano en bruto [roher Mensch] (Kant, 1983: 281-282; Anthropologie, Ak. 
$\mathrm{XV}:$ 780-782) ${ }^{2}$. Lo que se designa con estos conceptos -a pesar de su diferencia y dificultad de traducción- no dista mucho del lenguaje cotidiano. Mientras que la condición brutal o cruda (la Robigkeit) se erige como una substantivación del adjetivo roh -como aquella condición en la que no ha existido elaboración alguna-, el concepto de ser humano en bruto (el Rohmensch o roher Mensch) se refiere a dicho ser humano que, en tanto parte de dicha condición original, no conoce u ostenta más que su cualidad fisiológica. Aun cuando Kant destaca el carácter violento e intimidante del estado de crudeza en que se encuentra el ser bumano en bruto (Kant, 1983: 281), no puede ignorarse el hecho de que tal situación de conflicto tenga lugar justamente gracias a la constitución fisiológico-animal en la que ella descansa. En este sentido, la condición de crudera debe ser siempre entendida como animalidad (Kant, 1977: 516-517). "Un ser humano en bruto es: el que no ha recibido ninguna disciplina"; el que, como se verá más abajo, aún no ha adquirido "la disciplina de la razón" (Anthropologie, Ak. XV: 782) y sólo dispone de aquel equipamiento técnico animal recibido al nacer.

La forma en que Kant comprende dichas figuras en bruto no resulta accidental, sino que expresión de una toma de posición general que, si bien carece de una elaboración sistemática, no puede ser desatendida. En Reflexionen zur Moralphilosophie Kant resume esta posición. En el marco de aquello que delimita como parte "del ordenamiento de la contemplación del ser humano", Kant sostiene en el punto 4. que "el estado de la naturaleza" es "un ideal de las relaciones externas de lo meramente natural, a saber: del ser humano en bruto [des Rohen Menschen]" (Moralphilosophie, Ak. XIX: 99). Con ello no sólo se torna claro que el ser bumano en bruto esté en directa concordancia con la dimensión fisiológica - predeterminada por la naturaleza-, sino también que aquella observación deba ser comprendida como un ideal, esto es, como producto de una hipótesis de tipo teórica. Por cierto que las observaciones de tipo empírico quedan con ello prácticamente borradas. Sin embargo, esto último no significa que dicha referencia a la dimensión fisiológica ideal del ser humano pierda valor. A pesar de que no existen seres bumanos en bruto propiamente tales, y esto supone según Gehlen (1966: 38) que "no hay ninguna sociedad humana sin armas, sin fuego, sin alimento preparado y artificial, sin techo y sin formas de cooperación organizada", aquello no excluye la posibilidad de considerar dicha condición-como lo ha hecho, a pesar de sus diferencias, la tradición del derecho

2 Las referencias a Kant que no van acompañadas por el año son citadas según la paginación canónica de la Akademie-Ausgabe, Gesammelte Schriften (Kant, 1900 ss). La citación se indica por medio del título correspondiente, seguida por el número de tomo y el número de página. 
natural- como hipótesis lógica o experimento analítico. Con ello se destaca entonces una dimensión en la que según Kant (1983: 29) la naturaleza predetermina al ser humano y se abre, por lo mismo, la posibilidad de pensarlo con prescindencia de su posterior inclusión y participación en el mundo cultural. Aquí, sin embargo, no se acaba la cuestión.

\section{LA DIMENSIÓN CULTURAL DEL SER HUMANO}

A través de su participación y consecutiva creación de la realidad cultural emerge el complemento de la concepción fisiológica del ser humano. Al poner la dimensión cultural bajo la lupa, aparece aquella condición antropológica que puede ser propiamente entendida como histórica. El objeto de dicha perspectiva antropológica es entonces el ser humano que, una vez inmerso en el mundo, es comprendido como un ser cultural. Esta consideración apunta por lo mismo a tales competencias o propiedades que el ser humano ya no ha adquirido desde su nacimiento, sino que ha desarrollado sólo en y gracias a tal mundo cultural. Kant mismo observó que una comprensión del ser humano que se limite a lo fisiológico le denegaría a éste cualquier movimiento libre. El ser humano no es sólo miembro del reino animal, sino que también de una comunidad dentro de la cual éste debe decidir. Por consiguiente, se esclarece el hecho de que el ser humano no "quede prefijado unívocamente por sus condiciones naturales" y que, dentro de un "margen de posibilidades (...) pueda incidir en la configuración de sí mismo como ser humano concreto y persona” (Becker, 1983: 21). Mientras la dimensión fisiológica o natural funge como condición basal del ser humano, dicha dimensión cultural es comprendida como su despliegue, si no incluso como su fin último (Anthropologie, Ak. XV: 888).

La distinción programática de la antropología kantiana habla por sí misma: el ser humano no es sólo resultado de lo que la naturaleza predetermina, sino que además de aquello que él hace, puede o debe hacer de sí mismo. Lo que el ser humano hace de su equipamiento técnico natural, "qué tipo de ser humano quiere ser", todo ello permanece -hasta un grado difícil de diagnosticar- a su discreción (Landmann, 1969: 8). Al interior de esta dimensión sólo puede ser la razón la que se erige en Kant como soporte. Aquella antropología pragmática de la cual Kant se hace cargo investiga por lo mismo al ser humano "como un ser dotado de razón", que deja de ser mero objeto de la naturaleza y emerge como consecuencia de aquello que éste hace de sí mismo en virtud de esta cualidad (Sturm, 2010). La razón en una criatura queda entonces definida como "una capacidad de ampliar las reglas y propósitos del uso de todas las fuerzas más allá del instinto natural" (Abhandlungen nach 1781, Ak. VIII: 18). La libertad que se pone en juego allí donde el ser humano co-determina su vida cultural, no 
levita en el aire, sino que está directa e íntimamente conectada con esta facultad (Kant, 1983: 233). A partir de lo mismo, se entiende que "el mayor secreto de la perfección de la naturaleza humana" (Logik. Physische Geographie, Pädagogik, Ak. IX: 444) -y con ello el optimismo kantiano- resida en dicha dimensión. Para abandonar parcialmente la crudez̧a o brutalidad de su condición animal, el ser humano debe "acostumbrarse a someterse a los preceptos de la razón” (Logik. Physische Geographie, Pädagogik, Ak. IX: 442). Mientras "la crudeza o brutalidad se confronta con la cultura", el instinto natural lo hace "con la razón" (Anthropologie, Ak. XV: 636). Llegado dicho momento, el ser humano puede elevarse más allá de su sustrato fisiológico y con ello "la humanidad" desplegarse a sí misma "desde sus gérmenes" (Logik. Physische Geographie, Pädagogik, Ak. IX: 445).

La ruptura fundamental del ser humano con su crudeza animal, que se desencadena en esta dimensión cultural y se expresa en Kant a través del concepto de razón, tiene lugar también en los representantes de la antropología filosófica del siglo XX. Un vistazo a sus núcleos teóricos deja ver elementos ciertamente semejantes a la idea de razón. En Scheler esta oposición particular respecto del principio vital asoma clara: "[e]l nuevo principio está fuera de todo aquello que podemos designar como 'vida'. Eso que hace únicamente humano al ser humano no es una etapa nueva de la vida (...), sino que es un principio opuesto a toda y a cada vida, también a la vida en el ser humano: un hecho esencial nuevo que como tal no puede ser atribuido de ninguna manera a la 'evolución natural de la vida"' (Scheler, 2010: 27). Si el primer polo del equilibrio, como hemos visto, está marcado por la corporalidad o el impulso vital general, el segundo polo adopta una forma cultural análoga a la de razón; una forma que, como en Kant, debe dirigir a la fisiológica y hace posible el levantamiento del ser humano por sobre el mundo animal. Aquella figura queda expuesta en el concepto de espiritu [Geist]. A diferencia de los animales, cuyas perspectivas están siempre atadas al mundo circundante, el ser humano está en condiciones de trascender dicha barrera. Mediante la idea de espiritu se distingue -en palabras de Scheler- a un ser que, en contraposición al animal, ya "no está atado a sus impulsos, a su entorno, sino que es libre" "y está 'abierto-al-mundo' [weltoffen]" (Scheler, 2010: 28). La idea de apertura-al-mundo [Weltoffenheit] que posibilita el concepto de espiritu apunta justamente a la facultad que tiene el ser humano de generar una consideración u observación con distancia; una contemplación que, por cierto, no excluye su potencial negación. Dicho ser que, como afirma Scheler, tiene mundo estaría en condiciones de distanciarse conscientemente de su entorno y sus impulsos para incluso adoptar una actitud disruptiva y, llegado el caso, negarlos. La idea completa de espiritu de aquel que además puede-decir-no [Neinsagenkönner] da cuenta entonces de propiedades o competencias generales que se profundizarán 
luego junto al concepto de sujeto, esto es: "distanciamiento, objetividad, autoconsciencia y conducta de vida", entre otros (Rehberg, 1981: 168).

Si en Plessner la dimensión fisiológica del carácter o aspecto doble del ser humano es vivida -como en los animales-en y por el cuerpo, posicionado céntricamente, el quiebre más evidente con dicha esfera animal está dado por la trascendencia cultural de la misma. En contraposición al animal o, lo que es en este caso lo mismo, a su condición fisiológica -atada al aquíy abora-, la vida del ser humano se levanta, según Plessner (1975: 291-291), "por sobre esta última, de manera excéntrica". Más allá de su equipamiento natural y de manera símil al concepto de espiritu en Scheler, se erige entonces la forma posicional excéntrica mediante reflexividad. "La excentricidad es la forma característica que tiene el ser humano para confrontarse con el ambiente" (Plessner, 1975: 292; destacado R.A.]; una circunstancia que confirma el hecho de que el cuerpo mismo del ser humano se ha vuelto objeto posible de reflexión. El animal no está en condiciones de tomar distancia respecto de su propio cuerpo. Sólo el ser humano puede ir más allá de aquél, de su centro. El ser humano vive, vivencia, pero también puede vivenciar su vivenciar, con lo cual se sobrepasa a sí mismo. Y es justamente esta distancia respecto de sí mismo lo que Plessner identifica -en oposición al ser-cuerpo fisiológico [Leibsein]- como un tener-cuerpo cultural [Körperbaben]. El ser humano es en virtud de su condición animal su-cuerpo, mientras que simultáneamente puede comportarse respecto del mismo como si éste fuera un objeto, a saber: excéntricamente (Habermas, 1985: 369). Solamente el ser humano puede estar entonces tanto adentro como afuera. En palabras de Plessner:

A la excentricidad de la estructura del ser vivo le corresponde la excentricidad de la situación o del doble aspecto no-derogable de su existencia [en tanto que ser y tener cuerpo] (...) ambas cosmovisiones son necesarias, el ser humano como cuerpo [Leib], en el centro de una esfera que, de manera correspondiente con su forma empírica, conoce el arriba, abajo, adelante, atrás, a la derecha, a la izquierda, antes y después, una perspectiva que sirve de base de la cosmovisión organológica, y el ser humano como cuerpo-objetual [Körperding] en una posición cualquiera de un continuo de sucesos posibles, una perspectiva que conduce a la concepción matemático-física. (Plessner, 1975: 294)

En el marco de la naturaleza carencial del ser humano descrita por la antropología filosófica surge, por otra parte, inevitablemente la interrogante: "¿cómo puede un ser tan desprotegido, necesitado y expuesto mantenerse vivo?” (Gehlen, 1966: 19). La respuesta a esta pregunta coincide 
justamente con aquello que Gehlen circunscribe a dicha dimensión cultural. Para ello se prestan conceptos como el de descarga y acción, los que de paso arrojan luz sobre el elemento fundamental de la idea de apertura-almundo de Scheler. Dado que el ser humano está fisiológicamente falto de "especialización", resulta inacabado, débil de instinto, etc., éste debe "descargarse, lo que significa que debe convertir las condiciones carenciales de su existencia autónomamente [a través de la acción; R.A.] en chances de prolongación de su vida" (Gehlen, 1966: 36). Sólo en la medida en que el ser humano se descarga o, dicho más abstractamente aún, se distancia de su condición carencial a través de la acción, éste puede permanecer vivo. Aquello que el ser humano fisiológicamente no puede obtener es compensado así mediante la acción y transformado en un poder-bacer general. Esta característica que distingue finalmente al ser humano como un ser actuante [handelndes $W e$ $s e n]$ encuentra su corolario en la naturaleza procesada que se reconoce en la cultura-como expresión de la totalidad de las instituciones resultantes de las dinámicas de descarga- y conforma "prácticamente una cubierta protectora de la vida humana, individual y social" (Schmied, 2007: 174). Así se cierra el círculo de la antropología filosófica de Gehlen: "El ser humano, para poder existir, está prediseñado para la transformación y superación de la naturaleza y, por lo mismo, para la posibilidad de la experiencia del mundo: él es un ser actuante debido a su no-especialización y a que, por tanto, carece de un entorno naturalmente adaptado. La quinta esencia de la naturaleza procesada por él se llama cultura, y el mundo cultural es el mundo humano" (Gehlen, 1966: 38).

Partiendo de la base de la razón (Kant), del espiritu (Scheler), de la posicionalidad excéntrica (Plessner), así como de la descarga posibilitada por la acción (Gehlen), queda claro que el ser humano no puede ser puramente entendido en términos fisiológicos. Nacido con competencias naturales, éste se ve incluido en un ambiente cultural en el que se desarrolla a sí mismo. En otras palabras: "Impulsos, afectos y reacciones del ser humano, originalmente abiertos e inadaptados, son modificados mediante la absorción (...) de elementos culturales (como normas, valores, lenguaje, símbolos, etc.)" (Henecka, 1997: 62). La debilidad de los instintos, el exceso de pulsiones y el equipamiento orgánico carencial, son todos compensados a través de un desarrollo que, si bien adquiere la forma de la razón, del espiritu, de una posicionalidad excéntrica y de la acción (Schnädelbach, 1983: 287), puede ser comprendido en términos generales a partir de la integración en el mundo cultural. Una vez nacido, el ser humano entra "en contacto con sus pares", gracias a los cuales surgen efecto las normas y formas culturales que "él debe adoptar" (Landmann, 1969: 159). A pesar de algunos déficits explicativos propios de la antropología filosófica, que tienen que ver con el proceso de internalización social de la cultura -elementos que no puedo 
tratar aquí (ver Alvear, 2020)-, se vuelve al menos evidente que la mencionada observación fisiológica no está en condiciones de esclarecer al ser humano en un sentido pleno. Por el contrario, el ser humano sólo puede ser comprendido plenamente a condición de que "a dichas propiedades [fisiológicas; R.A.] se le agregue su enraizamiento en el espíritu objetivo, a aquello definido por el nacimiento natural lo definido por la cultura, a aquello que es un patrimonio infinito y constante de su género lo que, si bien le pertenece irremediablemente a su género, puede sin embargo variar en contenido de pueblo en pueblo, de era en era" (Landmann, 1969: 186).

\section{El sujeto}

La constatación de la dimensión cultural del ser humano encuentra también su correlato en la forma o imagen que encarna el mismo a este nivel. Esta dimensión que acentúa lo que el ser humano hace, puede y/o debe hacer de sí mismo, se corresponde con aquella faceta que ha sido comprendida teóricamente junto al concepto de sujeto. Aquí se pone en juego una suerte de trascendencia cultural de lo fisiológico o, dicho con otras palabras, una conversión cultural del equipamiento natural congénito al ser humano. Al denominado ser bumano en bruto le están a disposición una serie de competencias fisiológicas que, con su participación en el mundo cultural, serían complementadas por nuevas facultades que le permiten superar parcialmente dicha condición primaria. Kant mismo se refiere a esta circunstancia cuando se trata del concepto de razón. El ser humano que "viene al mundo crudo o en bruto [roh auf die Welt]" (Logik. Physische Geographie, Pädagogik, Ak. IX: 441) sólo puede ir más allá de aquel estado natural-original en virtud de su adopción de la razón. No es sino hasta que aparece la razón, que el ser humano puede llevar a cabo aquella suerte de lustrado o "pulimento de su brutalidad" (Logik. Physische Geographie, Pädagogik, Ak. IX: 443) que lo encumbra por sobre su cualidad animal. Este levantamiento del ser humano por sobre "la crudeza de la mera autoviolencia" natural tiene lugar a través de la civilización y la cultura con ella resultante, que lo transforma al mismo tiempo en un ser civilizado con razón y libertad (Kant, 1983: 281). Tan pronto como el ser bumano en bruto, con su impulso vital y carencias, se integra al mundo cultural, su "animalidad" quedaría entonces entregada y subordinada "a la razón" (Anthropologie, Ak. $\mathrm{XV}:$ 782), para con ello convertirse en sujeto.

La igualdad de la especie humana o, lo que es lo mismo, de los seres bumanos en bruto se transforma en el mundo cultural -abierto para igualdades y desigualdades- en una unidad de sujetos (Anthropologie, Ak. XV: 781) que trascienden por tanto sus materias primas fisiológicas. Cimentado en lo anterior y más allá de distinciones específicas, se entiende entonces que 
para la antropología filosófica en general el proceso de humanización plena, de subjetivización propiamente tal, quede definida como una suerte de "transición hacia la apertura-al-mundo" a fuer de la razón (Kant), "del espiritu" (Scheler, 2010: 29), de la posicionalidad excéntrica (Plessner) o de la acción (Gehlen). El proceso de subjetivización no sería entonces otra cosa que un proceso de "racionalización" (Kant), de "espirituación" (Scheler), de "excentralización” (Plessner) o de "accionalización" (Gehlen) de la naturaleza o vida, a partir de la cual el ser humano en bruto se transforma en sujeto. Con su inclusión en el mundo cultural el ser bumano en bruto comenzaría entonces, como sostienen Kant y los posteriores representantes de la antropología filosófica, a internalizar aptitudes paralelas como las de autoconsciencia, toma de distancia, objetividad y acción. En este sentido, la categoría de sujeto designa a aquel ser humano capaz "de autodeterminarse de manera libre", lo que significa que, afincado en su autoconsciencia excéntrica, está en condiciones de tomar distancia "objetiva" y actuar racionalmente, esto es: con "consciencia o intencionalidad" (Bertschi, 2010: 59).

Más allá de la especificidad de las diversas definiciones que se expanden a este nivel, lo que queda claro es esta suerte de ruptura o distinción definitiva respecto de la dimensión animal del ser humano. Según Peter V. Zima, esta diferenciación no sólo sería comprensible desde un punto de vista analítico o teórico, sino que resultaría incluso observable en la vida cotidiana: "Al ser individual que encontramos en la calle o a campo abierto lo reconocemos como individuo [como ejemplar único de la especie humana, en tanto que ser bumano en bruto; R.A.], pero no como sujeto. No es sino hasta que él mismo se da a conocer a través de la palabra y sus actos que lo percibimos como sujeto" (Zima, 2007: 8). Por cierto que un individuo a pie no puede ser comprendido como ser bumano en bruto propiamente tal, en la medida en que éste ha comenzado a abandonar -al menos parcialmente- dicha condición desde su nacimiento. Sin embargo, lo que de todos modos se vuelve evidente es que el ser-sujeto no puede ser circunscrito a un proceso pasivo. Ser-sujeto no significa otra cosa que participar o poder participar activamente en la reproducción de la realidad cultural a través de aquellas categorías que, según la antropología filosófica, han podido emerger gracias a la misma, a saber: la razón, el espiritu, la posicionalidad excéntrica y/o la acción.

\section{REFLEXIONES FINALES: ACERCA DE UNA RELACIÓN ÍNTIMA}

Si se observan las ideas o imágenes de ser humano en bruto y sujeto desde una perspectiva más abstracta, no resulta difícil identificar la relación de afinidad interna que se pone en juego. La imbricación de ambas dimensiones da cuenta de la idea de ser humano en su totalidad. Al respecto, sería 
posible constatar incluso una vinculación particular que opera como una suerte de lejana analogía a la estructura evolucionaria del modelo basesuperestructura descrito por Marx; el que no por nada parece resumir el leitmotiv de la antropología filosófica en general. Observado en términos abstractos puede advertirse cómo la dimensión cultural del ser humano (sujeto) se alza teniendo a la dimensión fisiológica (ser bumano en bruto) como base material, como presuposición indispensable. Este diagnóstico, como se ha visto, se puede percibir en la antropología de Kant, Scheler, Plessner y Gehlen. Aun cuando Kant opta por desistir del propósito de desarrollar sistemáticamente la perspectiva de una antropología fisiológica en favor de la antropología pragmática, no puede pasarse por alto el hecho de que sólo aquella criatura que tiene un equipamiento técnico natural compatible con la misma puede transformarse en un ser racional [Vernunftwesen] (Kant, 1983: 233). El estado cultural que surge con lo anterior está compuesto así por "personas con meras propiedades naturales" (Moralphilosophie, Ak. XIX: 99), cuyas cualidades han sido disciplinadas a través de la educación. Así queda claro que el "ser humano natural" o ser bumano en bruto llegado el caso pueda "[corresponderse] con el ser humano racional" propiamente tal (Anthropologie, Ak. XV: 888).

De manera símil a lo precedente puede comprenderse la relación del espiritu con la vida en Scheler. Dicho resumidamente: sin vida no hay espiritu. "Por cierto que el espíritu puede ganar poder a través del proceso de sublimación (...) pero el espiritu, por sí mismo y de manera original, no tiene energía propia" (Scheler, 2010: 48). El espíritu rector carece de fuerza, en sí mismo no es un factor realizador, sino que meramente determinador $-\mathrm{y}$ siempre a fuer de la vida (Agard, 2013: 186). En Plessner, la fórmula se repite. La forma de organización céntrica del ser humano que se apoya en la idea del ser-cuerpo [Leibsein] es la base para la excentricidad que luego se manifiesta en la disposición abierta al mundo del tener-cuerpo [Körperbaben]. Plessner mismo insistió al respecto: la vida del ser humano se expresa, como se ha dicho, "sin poder romper con la centralización, por sobre esta última, de manera excéntrica” (Plessner, 1975: 292). La excentricidad debe por tanto ser vivida en el cuerpo. Sólo en la medida en que el ser humano permanece atado a su centro, a su cuerpo animal, puede luego dar el paso de quiebre distintivo a su especie y distanciarse excéntricamente del mismo -sin entonces abandonarlo del todo. La apertura-al-mundo que con ello queda a disposición, se enraiza en aquella distancia en el cuerpo respecto del cuerpo [Abstand im Körper zum Körper] (Fischer, 2013: 43), que sólo puede tener lugar en una figura total -en este caso bidimensional- de ser humano. En la teoría de Gehlen el proceder es nuevamente similar. El filósofo de la Escuela de Leipzig observó en la carencia de órganos altamente adaptados al entorno, así como en el exceso general de impulsos, la base o la necesidad biológica 
que explica el giro activo del ser humano a su entorno cultural (Gehlen, 1966: 31-40; Griese, 1976: 38). Como señalara él mismo: "En el ser humano, la falta de especialidad de su construcción [orgánica; R.A.] se corresponde con su apertura-al-mundo" (Gehlen, 1966: 38). El ser humano hace de su necesidad una virtud. Si éste puede descargarse de su realidad circundante mediante la acción y así llevar una vida abierta-al-mundo, esto ocurre por tanto en virtud de su incompletitud fisiológica.

Dicho en otros términos: sin dependencia-respecto-del-mundo no existe apertura-al-mundo [ohne Weltgebundenheit keine Weltoffenheit], ipero no necesariamente a la inversa! Mientras que todos los sujetos que toman parte en el mundo cultural desarrollan una perspectiva abierta-al-mundo a través del despliegue de la razón (Kant), del espiritu (Scheler), de una posicionalidad excéntrica (Plessner) y/o de la acción (Gehlen), las que presuponen a su vez una batería de competencias fisiológicas -como impulso afectivo, memoria asociativa, inteligencia, etc.-, los seres bumanos en bruto no necesariamente deben presuponer o activar las características culturales mencionadas en caso de permanecer en el exterior a dicha vida cultural. La tesis frecuentemente sostenida de que sólo los seres bumanos serían sujetos resulta según esta óptica verdadera y falsa al mismo tiempo. Por una parte, se vuelve evidente que sólo los seres humanos son capaces de ser sujetos, en la medida en que -distinto a ciertas direcciones pos-modernas y pos-estructuralistas- el serbumano en bruto es una precondición ineludible para el desarrollo de las propiedades culturales. Sin embargo, dicha afirmación sería por otra parte igualmente falsa, dado que no resulta suficiente ser fisiológicamente humano para poder ser sujeto y desplegar con ello tales facultades. Sólo aquel que participa de la vida cultural y que gracias a la misma desarrolla "un conocimiento claro de su punto de vista y de su relación práctica respecto del mundo" (Becker, 1983: 23); sólo aquel que entonces obra abierto-almundo está estrictamente en condiciones de convertirse en y operar como sujeto. Naturaleza y cultura asoman así cuasi indelebles. En dicha bidimensionalidad íntimamente entrelazada se juega aquello que según la antropología filosófica captura el núcleo de lo que significa ser-bumano en su totalidad.

\section{REFERENCIAS}

Agard, O. (2013). Max Scheler: Anthropologie und Historismus. En G. Plas, G. Raulet y M. Gangl (Ed.), Philosophische Anthropologie (pp. 175-198). Deutschland: Traugott Bautz.

Alvear, R. (2020). Soziologie obne Mensch? Umrisse einer soziologischen Anthropologie. Bielefeld: Transcript. 
Becker, W. (1983). Einleitung. Kants pragmatische Anthropologie. En I. Kant, Anthropologie in pragmatischer Hinsicht (pp. 9-26). Stuttgart: Reclam.

Bertschi, S. (2010). Im Dazwischen von Individuum und Gesellschaft. Bielefeld: Transcript.

Claessens, D. (1973). Anthropologische Voraussetzungen einer Theorie der Sozialisation. Zeitschrift für Soziologie, 2(2), 145-162.

Eßbach, W. (2007). Denkmotive der philosophischen Anthropologie, Journal Philosophie der Psychologie. http://www.jp.philo.at/texte/EssbachW1.pdf

Fischer, J. (2006). Der Identitätskern der Philosophischen Anthropologie (Scheler, Plessner, Gehlen). En H. Krüger y G. Lindemann G. (Ed.), Philosophische Anthropologie im 21. Jahrhundert (pp. 63-82). Berlin: Akademie Verlag.

Fischer, J. (2013). Soziologie aus der Perspektive der Philosophischen Anthropologie. En M. Corsten y M. Kauppert (Ed.), Der Mensch - nach Rücksprache mit der Soziologie (pp. 33-60). Frankfurt am Main: Campus.

Gehlen, A. (1966). Der Mensch. Seine Natur und seine Stellung in der Welt. Frankfurt am Main/Bonn: Athenäum.

Gehlen, A. (1983). Philosophische Anthropologie und Handlungslehre. Frankfurt am Main: Klostermann.

Griese, H. (1976). Soziologische Anthropologie und Sozialisationstheorie. Weinheim/Basel: Beltz.

Habermas, J. (1962). Anthropologie. En A. Diemer y I. Frenzel (Ed.), Philosophie (pp. 18-35). Frankfurt am Main: das Fischer Lexikon.

Habermas, J. (1985). Der philosophische Diskurs der Moderne. Zwölf Vorlesungen. Frankfurt am Main: Suhrkamp.

Heidegger, M. (1997). Sein und Zeit. Frankfurt am Main: Verlag Vittorio Klostermann.

Henckmann, W. (1998). Max Scheler. München: Beck.

Henecka, H. (1997). Grundkurs Soziologie, Opladen, Leske+Budrich.

Horkheimer, M. (1935). Bemerkungen zur philosophischen Anthropologie. Zeitschrift für Sozialforschung, 4(1), 1-25.

Kant, I. (1900 ss). Kants gesammelte Schriften (Ak., 29 vols., Koeniglichen Preussischen Akademie der Wissenschaften, Ed.). Berlin: Walter de Gruyter.

Kant, I. (1977). Die Metaphysik der Sitten. Frankfurt am Main: Suhrkamp.

Kant, I. (1978). Logik. Ein Handbuch zu Vorlesungen. En W. Weischedel (Ed.), Schriften zur Metaphysik und Logik (pp. 421-582). Frankfurt am Main: Suhrkamp.

Kant, I. (1983). Anthropologie in pragmatischer Hinsicht. Stuttgart: Reclam.

König, R. (1965). Soziologische Orientierungen. Köln/Berlin: Kiepenheuer und Witsch.

Kurtz, T. \& Pfadenhauer, M. (2010). Soziologie der Kompetenz. Wiesbaden: VS Verlag für Sozialwissenschaften.

Kurtz, T. (2010). Der Kompetenzbegriff in der Soziologie. En T. Kurtz y M. Pfadenhauer (Ed.), Soziologie der Kompetenz. Wiesbaden: VS Verlag für Sozialwissenschaften. 
Landmann, M. (1962). De Homine. Freiburg/München: Karl Alber.

Landmann, M. (1969). Philosophische Anthropologie. Berlin: Walter de Gruyter.

Lepenies, W. (1977). Soziologische Anthropologie. München: Carl Hanser.

Lukács, G. (1923). Geschichte und Klassenbewußtsein. Studien über marxistische Dialektik.

Müller, O. y Heilinger, J. (2008). Zehn Thesen zur „Natur des Menschen“. Grundriss zu einer Anthropologie. En G. Detlev, V. Gerhardt, J. Heilinger y J. Nida-Rümelin (Ed.), W as ist der Mensch? (pp. 190-196). Berlin/New York: Walter de Gruyter.

Plessner, H. (1975). Die Stufen des Organischen und der Mensch. Berlin/New York: Walter de Gruyter.

Raulet, G. (2013). ,Jenseits des Anthropologieverdachts. Das kritische Potential der Philosophischen Anthropologie“. En G. Plas, G. Raulet y M. Gangl (Ed.), Philosophische Anthropologie. Themen und Positionen (Bd.2, pp. 33-60). Deutschland: Verlag Traugott Bautz GmbH.

Rehberg, K. (1981). Philosophische Anthropologie und die „Soziologisierung“ des Wissens vom Menschen. Kölner Zeitschrift für Soziologie und Sozialpsychologie, 23, 160-198.

Scheler, M. (1929). Philosophische Weltanschaunng. Bonn: Cohen.

Scheler, M. (2010). Die Stellung des Menschen im Kosmos. Bonn: Bouvier.

Schmied, G. (2007). Das Rätsel Mensch - Antworten der Soziologie. Opladen: Barbara Budrich.

Schnädelbach, H. (1983). Philosophie in Deutschland 1831-1933. Frankfurt am Main: Suhrkamp.

Sobrevilla, D. (2006). El retorno de la Antropología filosófica. Diánoia, (56), 95124.

Sturm, T. (2010). Warum hat Kant physiologische Erklärungen in seiner Anthropologie zurückgewiesen? En Gerhardt y J. Nida-Rümelin (Eds), Evolution in Natur und Kultur (pp. 77-102). Berlin/New York: De Gruyter.

Zima, P. (2007). Theorie des Subjekts. Tübingen: UTB. 